\title{
Synthesis of Fe-Si-B-Mn-based nanocrystalline magnetic alloys with large coercivity by high energy ball milling
}

\author{
P D REDDI ${ }^{1}$, N K MUKHOPADHYAY ${ }^{1}$, B MAJUMDAR ${ }^{2}$, A K SINGH ${ }^{2}$, S S MEENA ${ }^{3}$, \\ S M YUSUF ${ }^{3}$ and N K PRASAD ${ }^{1, *}$ \\ ${ }^{1}$ Department of Metallurgical Engineering, Indian Institute of Technology, Banaras Hindu University, \\ Varanasi 221005 , India \\ ${ }^{2}$ Defence Metallurgical Research Laboratory, Kanchanbagh, Hyderabad 500 058, India \\ ${ }^{3}$ Solid State Physics Division, Bhabha Atomic Research Centre, Mumbai 400 085, India
}

MS received 24 June 2013; revised 15 July 2013

\begin{abstract}
Alloys of $\mathrm{Fe}-\mathrm{Si}$-B with varying compositions of Mn were prepared using high energy planetary ball mill for maximum duration of $120 \mathrm{~h}$. X-ray diffraction (XRD) analysis suggests that Si gets mostly dissolved into Fe after $80 \mathrm{~h}$ of milling for all compositions. The residual Si was found to form an intermetallic $\mathrm{Fe}_{3} \mathrm{Si}_{\text {. The }}$ dissolution was further confirmed from the field emission scanning electron microscopy/energy dispersive $\mathrm{X}$-ray analysis (FE-SEM/EDX). With increased milling time, the lattice parameter and lattice strain are found to increase. However, the crystallite size decreases from micrometer $(75-95 \mu \mathrm{m})$ to nanometer $(10-20 \mathrm{~nm})$. Mössbauer spectra analysis suggests the presence of essentially ferromagnetic phases with small percentage of super paramagnetic phase in the system. The saturation magnetization $\left(M_{\mathrm{s}}\right)$, remanance $\left(M_{\mathrm{r}}\right)$ and coercivity $\left(H_{c}\right)$ values for $\mathrm{Fe}-0 \mathrm{Mn}$ sample after $120 \mathrm{~h}$ of milling were $96.4 \mathrm{Am}^{2} / \mathrm{kg}, 11.5 \mathrm{Am}^{2} / \mathrm{kg}$ and $12.42 \mathrm{k} \mathrm{Am}^{-1}$, respectively. However, for $\mathrm{Fe}-10 \mathrm{Mn}-5 \mathrm{Cu}$ sample the $M_{\mathrm{s}}, H_{\mathrm{c}}$ and $M_{\mathrm{r}}$ values were found to be $101.9 \mathrm{Am} / \mathrm{kg}$, $10.98 \mathrm{kA} / \mathrm{m}$ and $12.4 \mathrm{Am}^{2} / \mathrm{kg}$, respectively. The higher value of magnetization could be attributed to the favourable coupling between $\mathrm{Mn}$ and $\mathrm{Cu}$.
\end{abstract}

Keywords. Mechanical alloying; lattice strain; amorphization; magnetic properties.

\section{Introduction}

Various non-equilibrium processing techniques have been employed during the past few decades to develop novel and advanced materials with improved performance. Amongst such processes, mechanical milling/alloying has received considerable attention from researchers (Koch 1993; Suryanarayana et al 2001). Mechanical milling/alloying is employed for the synthesis of amorphous and other materials including rare earth permanent magnets and ferrites (Okumura et al 1992; Koch 1993; Suryanarayana et al 2001). During this process, longrange order of the materials is disrupted to produce an intermetallic or alloy or an amorphous phase of nanometric dimension (Koch 1993; Suryanarayana et al 2001). The milling process depends on the factors like type of mill, balls and container, milling speed, milling time, size of starting powder, grinding medium, ball-topowder weight ratio, extent of rolling the vial, milling atmosphere and temperature of milling (Okumura et al 1992; Koch 1993). Components produced after the compaction and sintering of milled powder find structural

*Author for correspondence (nandkp.met@itbhu.ac.in) applications in aerospace and chemical industries. Production of magnetic components by this method opens up new possibilities.

Magnetic soft alloys based on Fe are key to success of power electrical industry, where these alloys are used in transformers, chokes, filters, etc whereas hard magnetic materials are used as permanent magnets. These soft magnetic materials have high saturation magnetization and suitable values of coercivity, remanance and resistivity for such applications (Filho et al 2000; Yapp et al 2000). In contrast, it is extremely difficult to process the high silicon content ( $>4 \mathrm{wt} \%$ ) Fe-Si alloys by conventional methods due to the limited solubility of Si. Nevertheless, there are a number of reports on the production of $\mathrm{Fe}-\mathrm{Si}$ based alloy with other elements like B, Mn, Al, etc by high energy ball milling (Perez et al 1995; Liu et al 1999; Yapp et al 2000; Hosseini and Bahrami 2005). The magnetic and Mössbauer studies on such materials are a few.

Here, we report the synthesis of $\mathrm{Fe}-\mathrm{Si}-\mathrm{B}$ system with increased weight percentage of Mn using high energy ball mill. The effect of $\mathrm{Mn}$ on the structural and magnetic behaviour of $\mathrm{Fe}-\mathrm{Si}$-B was studied using X-ray diffraction (XRD), scanning electron microscope (SEM), vibrating sample magnetometer (VSM) and Mössbauer spectroscopy. 
Table 1. Compositions and designations of various samples used in present study. Magnetic parameters such as $M_{\mathrm{s}}\left(\mathrm{Am} \mathrm{m}^{2} / \mathrm{kg}\right)$, $M_{\mathrm{r}}(\mathrm{Am} / \mathrm{kg})$ and $H_{\mathrm{c}}(\mathrm{kA} / \mathrm{m})$ for various samples (obtained after $120 \mathrm{~h}$ of milling) are also listed.

\begin{tabular}{|c|c|c|c|c|c|c|c|c|c|}
\hline \multirow[b]{2}{*}{ Sample } & \multirow[b]{2}{*}{ Sample name } & \multicolumn{5}{|c|}{ Composition (wt\%) } & \multicolumn{3}{|c|}{ Magnetic parameters } \\
\hline & & $\mathrm{Fe}$ & $\mathrm{Si}$ & B & $\mathrm{Mn}$ & $\mathrm{Cu}$ & $M_{\mathrm{s}}$ & $M_{\mathrm{r}}$ & $H_{\mathrm{c}}$ \\
\hline $\mathrm{Fe}-6 \mathrm{Si}-8 \mathrm{~B}$ & $\mathrm{Fe}-0 \mathrm{Mn}$ & 86 & 6 & 8 & 0 & 0 & $96 \cdot 4$ & $11 \cdot 5$ & $12 \cdot 42$ \\
\hline $\mathrm{Fe}-6 \mathrm{Si}-8 \mathrm{~B}-1 \mathrm{Mn}$ & $\mathrm{Fe}-1 \mathrm{Mn}$ & 85 & 6 & 8 & 1 & 0 & $134 \cdot 8$ & $9 \cdot 4$ & $10 \cdot 27$ \\
\hline $\mathrm{Fe}-6 \mathrm{Si}-8 \mathrm{~B}-5 \mathrm{Mn}$ & $\mathrm{Fe}-5 \mathrm{Mn}$ & 81 & 6 & 8 & 5 & 0 & $84 \cdot 3$ & $10 \cdot 5$ & $8 \cdot 52$ \\
\hline $\mathrm{Fe}-6 \mathrm{Si}-8 \mathrm{~B}-10 \mathrm{Mn}$ & $\mathrm{Fe}-10 \mathrm{Mn}$ & 76 & 6 & 8 & 10 & 0 & $64 \cdot 7$ & $7 \cdot 6$ & 8.44 \\
\hline $\mathrm{Fe}-6 \mathrm{Si}-8 \mathrm{~B}-10 \mathrm{Mn}-5 \mathrm{Cu}$ & $\mathrm{Fe}-10 \mathrm{Mn}-\mathrm{Cu}$ & 71 & 6 & 8 & 10 & 5 & 101.9 & $12 \cdot 4$ & 10.98 \\
\hline
\end{tabular}

It has been reported that $\mathrm{Cu}$ which is a diamagnetic, after alloying with Mn can provide a magnetic moment of up to $2.4 \mu_{\mathrm{B}}$ per atom (Bacon 1962). Hence, we added $\mathrm{Cu}$ in the system to observe its effect on the structural and magnetic behaviours.

\section{Experimental}

Powders of iron, silicon, boron, manganese and copper of purity $99.5,98.5,99,99$ and $99.5 \%$, respectively and corresponding particles size of $53,74,74,74$ and $78 \mu \mathrm{m}$ were selected for the present study. All the powders were from LOBA CHEMIE and were used without any further modifications. Various samples of iron-based alloys with different compositions of $\mathrm{Fe}, \mathrm{Si}, \mathrm{B}, \mathrm{Mn}$ and $\mathrm{Cu}$ were prepared using high energy P5-planetary ball mill (PM 400, Retsch () ). The compositions and designations of the various samples are listed in table 1 .

Elemental powders of above stated compositions were initially mixed and then ball milled up to $120 \mathrm{~h}$. Milling was carried out in stainless steel vials of $250 \mathrm{~mL}$ and using 39 stainless steel balls, each one having a diameter of $10 \mathrm{~mm}$ and weight of $7.692 \mathrm{~g}$. Ball to powder (BPR) ratio was maintained as $10: 1$ during each milling process. The rotational speed of the mill was kept around $200 \mathrm{rpm}$. Milling was carried out in wet condition using toluene, which restricts oxidation of metal or alloys during the process. The mill was stopped for $30 \mathrm{~min}$ after $5 \mathrm{~h}$ of run. Samples were collected after an interval of 40,60, 80,100 and $120 \mathrm{~h}$ of milling for structural, microstructural and magnetic characterizations.

Structural characterization of various milled samples was carried out using powder XRD (PHILIPS, X'PERT $\mathrm{PRO}$ ) having $\mathrm{CuK} \alpha$ radiation in the range of $20-90^{\circ}$. Phase identification is performed by the usual method of comparative peak matching with the standard ICDD software. The crystallite size $(D)$ and lattice strain $(e)$ for mechanically milled powders were calculated from single line broadening of XRD peaks using Voigt modelling (Yadav et al 2005).

The crystallite size of the samples could be estimated as:

$$
D=\left(\lambda / \beta_{\mathrm{C}} \cos \theta\right),
$$

where $\beta_{\mathrm{C}}=$ Cauchy component width $=\left(a_{0}+a_{1} \psi+a_{2} \psi^{2}\right)$ $\beta, \lambda=$ wavelength:

$$
\theta=\text { Bragg angle, } \psi=2 \omega / \beta,
$$

$\beta=$ integral breadth $=$ total area under the peak divided by height of the peak and $a_{0}=2.0207, a_{1}=-0.4803$, $a_{2}=-1.7756$ from Cauchy constants from the Langford table.

The lattice strain could be calculated as (Yadav et al 2005):

$$
e=\left(\beta_{\mathrm{G}} / 4 \tan \theta\right),
$$

where $\beta_{\mathrm{G}}=$ Gaussian component $=\left(b_{0}+b_{1 / 2}(\psi-2 / \pi)^{1 / 2}+\right.$ $\left.b_{1} \psi+b_{2} \psi^{2}\right) \beta$ and $b_{0}=0.6420, b_{1 / 2}=1.4187, b_{1}=-2.2043$, $b_{2}=1.8706$ are the Gaussian constants.

The morphology of the ball milled powder was observed by SEM (FESEM, QUANTA 200 F). Energy dispersive X-ray analysis (EDX) software associated with SEM was used for quantitative analysis. Determination of the valence states as well as magnetic nature of $\mathrm{Fe}$ for the as powdered samples was done using Mössbauer spectroscopy (Nucleonix Systems Pvt. Ltd.). The detail about the process has been explained earlier (Prasad et al 2005). In brief, the spectrometer was operated in constant acceleration mode (triangular wave) in transmission geometry. $\mathrm{Rh}$ matrix with $\mathrm{Co}^{57}$ of strength $50 \mathrm{mCi}$ was used as a source. The velocity scale was calibrated using an $\alpha$-Fe metal foil (speed $0.29 \mathrm{~mm} / \mathrm{s}$ ). All the spectra were fitted using WinNormos fit programme assuming Lorentzian line shapes. In addition, magnetic characterization for saturation magnetization $\left(M_{\mathrm{s}}\right)$, remanent magnetization $\left(M_{\mathrm{r}}\right)$ and coercive field strength $\left(H_{\mathrm{c}}\right)$ values for as-prepared samples were carried out at $300 \mathrm{~K}$ using a VSM (Lakeshore, model 7410).

\section{Results and discussion}

Figure 1 shows XRD patterns for Fe-0Mn samples obtained after milling for different durations (40, 60, 80, 100 and $120 \mathrm{~h}$ ). The patterns suggest that the samples obtained after $60 \mathrm{~h}$ of milling do not show any peak of silicon. However, after $80 \mathrm{~h}$ of milling, the evolution of new phase $\left(\mathrm{Fe}_{3} \mathrm{Si}\right)$ is observed. The formation of the 
phase becomes prominent with increased milling time such as 100 and $120 \mathrm{~h}$. This suggests that B or Si were not completely dissolved after 60 of milling. Some parts of these elements might be soluble in iron and the rest might be contributing to the formation of new phase. The earlier study in this system also suggests that although the peaks of Si or B were not observed in XRD patterns, but they were found as a separate phase in the SEM analysis even after $64 \mathrm{~h}$ of milling (Perez et al 1995). It was observed that with increased milling time, the peaks become broader, which could either be due to decrease in crystallite size or due to amorphization of the alloy. Simultaneously, the (1 110 ) peak of $\mathrm{Fe}$ is found to be shifting slightly towards right (i.e. higher Bragg angle) which indicate more dissolution of the alloying elements with increased milling time. Boron was added to enhance amorphization process. However, its peaks were not observed due to its low atomic scattering factor.

XRD patterns of $\mathrm{Fe}-5 \mathrm{Mn}$ and $\mathrm{Fe}-10 \mathrm{Mn}-5 \mathrm{Cu}$ powders obtained after similar milling times of 40,60, 80,100 and $120 \mathrm{~h}$ were close to that of $\mathrm{Fe}-0 \mathrm{Mn}$ and are shown in figures 2 and 3 , respectively. For these two cases also, the disappearance of $\mathrm{Si}$ peaks was observed after $60 \mathrm{~h}$ of milling. It was found that dissolution of $\mathrm{Si}$ has increased with Mn content for both the samples. Similar to $\mathrm{Fe}-0 \mathrm{Mn}$, these samples also showed the formation of $\mathrm{Fe}_{3} \mathrm{Si}$ phase after $80 \mathrm{~h}$ of milling, however, the phase was less prominent in $\mathrm{Fe}-5 \mathrm{Mn}$ sample and it was least in $\mathrm{Fe}-10 \mathrm{Mn}-5 \mathrm{Cu}$ sample. This indicates that the presence of $\mathrm{Mn}$ improves the dissolution of $\mathrm{Si}$ and $\mathrm{B}$ which further improves with $\mathrm{Cu}$-addition. Copper was also found to contribute to amorphization and thus, the peaks for $\mathrm{Fe}-10 \mathrm{Mn}-5 \mathrm{Cu}$ samples become broader compared to that of $\mathrm{Fe}-0 \mathrm{Mn}$ and $\mathrm{Fe}-5 \mathrm{Mn}$ samples. There were no individual peaks for $\mathrm{Mn}$ or $\mathrm{Cu}$ or their alloys. The

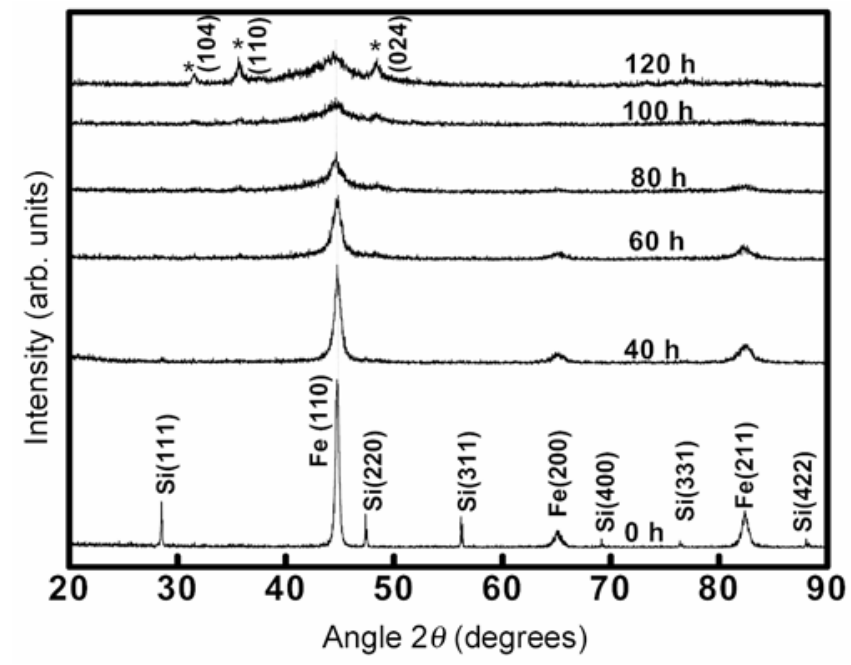

Figure 1. X-ray diffraction patterns of $\mathrm{Fe}-0 \mathrm{Mn}$ powder obtained after milling for various times $\left(*=\mathrm{Fe}_{3} \mathrm{Si}\right.$ phase). samples were identified to be $b c c$ structure. In contrast, researchers have observed transformation of bcc to fcc structure for Fe-24Mn and $\mathrm{Fe}-24 \mathrm{Mn}-6 \mathrm{Si}$ samples (Liu et al 1999). Similarly, other researchers have also observed the transformation of $\alpha$-Fe into $\gamma$-Fe in ball milled Fe-rich $\mathrm{Fe}-\mathrm{Cu}$ powder even at a composition of $\mathrm{Fe}-34 \mathrm{at} \% \mathrm{Cu}$ (Wu et al 1993; Majumdar et al 1997). However, in the present case, such transformations were not observed. This could be attributed to the presence of $\mathrm{Si}$ which did not allow this phase transformation. Nevertheless, the relatively less amount of substituent could be the other possibility. In contrast, the sample milled for longer duration showed amorphization due to the presence of $\mathrm{B}$. The different milling conditions might also have contributed here.

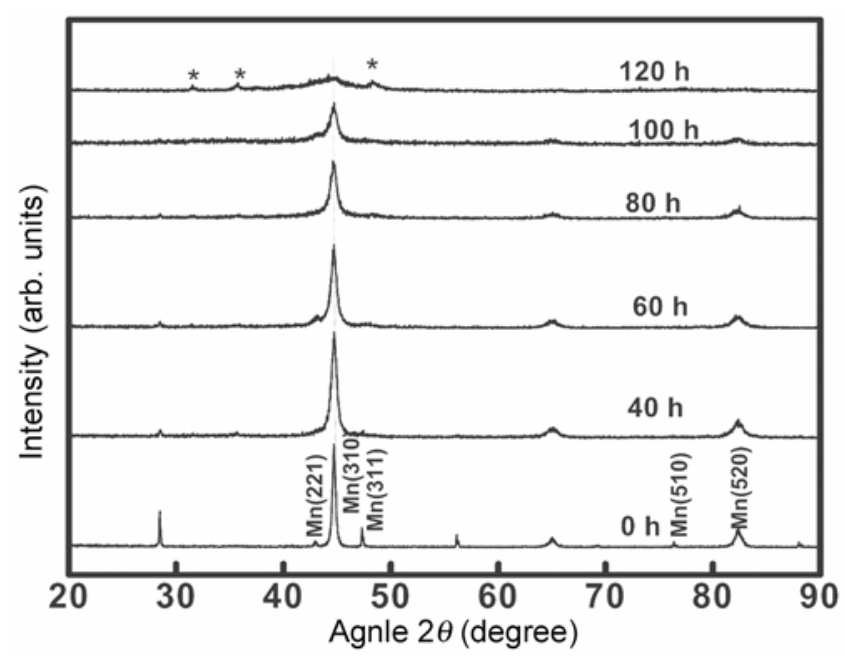

Figure 2. X-ray diffraction patterns of $\mathrm{Fe}-5 \mathrm{Mn}$ powder obtained after milling for various times $\left(*=\mathrm{Fe}_{3} \mathrm{Si}\right.$ phase).

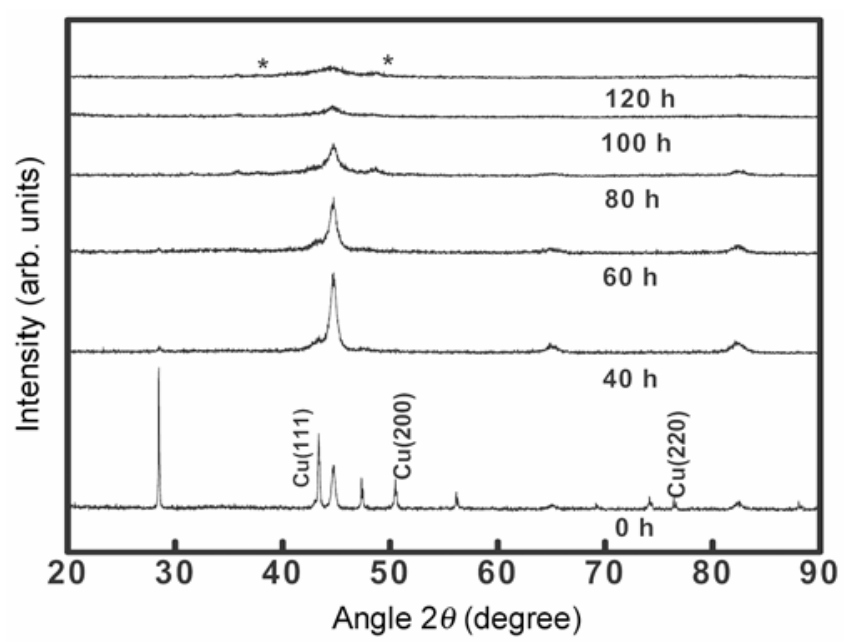

Figure 3. X-ray diffraction patterns of $\mathrm{Fe}-10 \mathrm{Mn}-5 \mathrm{Cu}$ powder obtained after milling for various times $\left(*=\mathrm{Fe}_{3} \mathrm{Si}\right.$ phase). 
With increased milling time, slight shift of the peaks of XRD patterns towards the lower $\theta$ value was observed for all three samples (figures 1-3). There was a gradual increase of lattice parameter of $b c c$ Fe due to the dissolution of substituents. XRD patterns for the samples obtained after $40 \mathrm{~h}$ of milling had prominently one peak (figures 1-3) and thus, the lattice parameter was calculated using Voigt modelling given in (1) (Yadav et al 2005). The variation of lattice parameter with milling time for different samples is shown in figure 4 . The reason for the increase of lattice parameter could be due to the formation of solid solution (Moumeni et al 2005). It was observed that the rise in the lattice parameter for the samples was not following a continuous trend. This may be because of dissimilar contribution of various elements such as $\mathrm{Mn}, \mathrm{Fe}, \mathrm{Cu}, \mathrm{Si}$ and $\mathrm{B}$ having atomic radii of 1.61 , $1.56,1.45,1 \cdot 11$ and $0.87 \AA$, respectively.

For various milled samples, the amount of lattice strain induced was also calculated using Voigt model from (2) (Yadav et al 2005) and the values are shown in figure 5. Due to the involvement of steady high energy forming process such as ball milling, the generations of dislocation densities in the systems are inevitable (Suryanarayana 2001; Mohamed 2003). For all the samples, the strain increased continuously with milling time. The crystallite size, estimated for various samples after different milling times using Voigt model from (1) (Yadav et al $2005)$ are shown in figure 6. Initially, crystallite size of the powders was in the range of $\mu \mathrm{m}$ which reduced to $\sim 75-95 \mathrm{~nm}$ after $40 \mathrm{~h}$ of milling (figure 6). With increasing milling time, the size further reduced and it was found to be $\sim 15-25 \mathrm{~nm}$ after $120 \mathrm{~h}$ of milling. The reduction of crystallite size of various samples can be attributed to the strain hardening and subsequent strain relaxation due to dynamic recovery caused during milling (Ares and Cuevas 2005; Ebrahimi et al 2011).

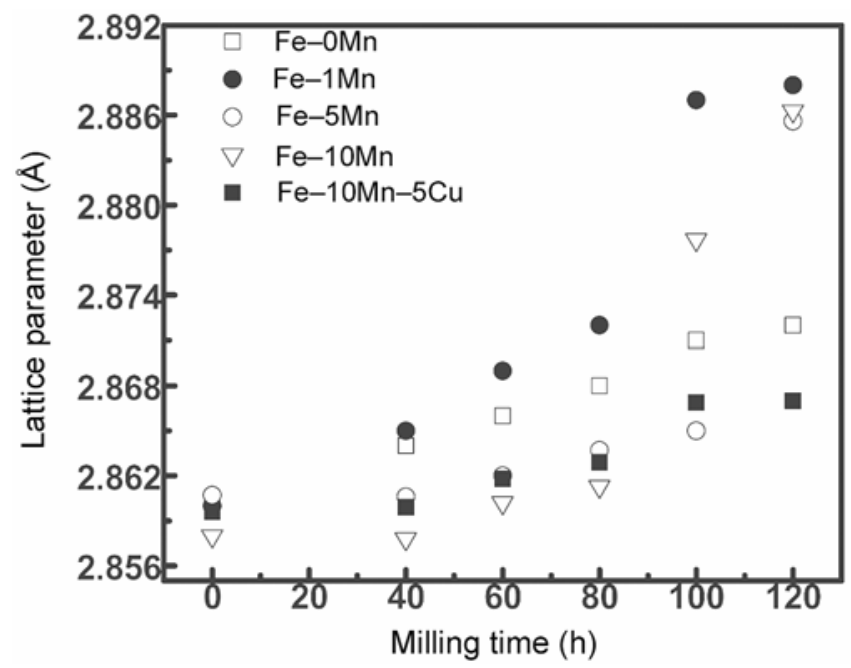

Figure 4. Variation of lattice parameter vs milling time for various samples.
Typical SEM micrographs of $\mathrm{Fe}-0 \mathrm{Mn}$ and $\mathrm{Fe}-1 \mathrm{Mn}$ powders obtained after $100 \mathrm{~h}$ of milling are shown in figure 7 . The micrographs suggest that the particles were in agglomerated form. This could be attributed to the continuous welding and fracture mechanisms during milling of ductile-ductile systems (Moumeni et al 2005; Ebrahimi et al 2011). The elemental analysis using EDX for the particles (whether grey or bright) suggests that the samples had essentially Fe and $\mathrm{Si}$. There was no separate peak for $\mathrm{Si}$ or $\mathrm{Fe}$ or $\mathrm{Mn}$. This further confirms the dissolution of $\mathrm{Si}$ in $\mathrm{Fe}$ which occurs during ball milling as observed in XRD results.

Mössbauer spectra analysis for the powder samples (e.g. $\mathrm{Fe}-0 \mathrm{Mn}, \mathrm{Fe}-1 \mathrm{Mn}, \mathrm{Fe}-3 \mathrm{Mn}, \mathrm{Fe}-5 \mathrm{Mn}, \mathrm{Fe}-10 \mathrm{Mn}$ and

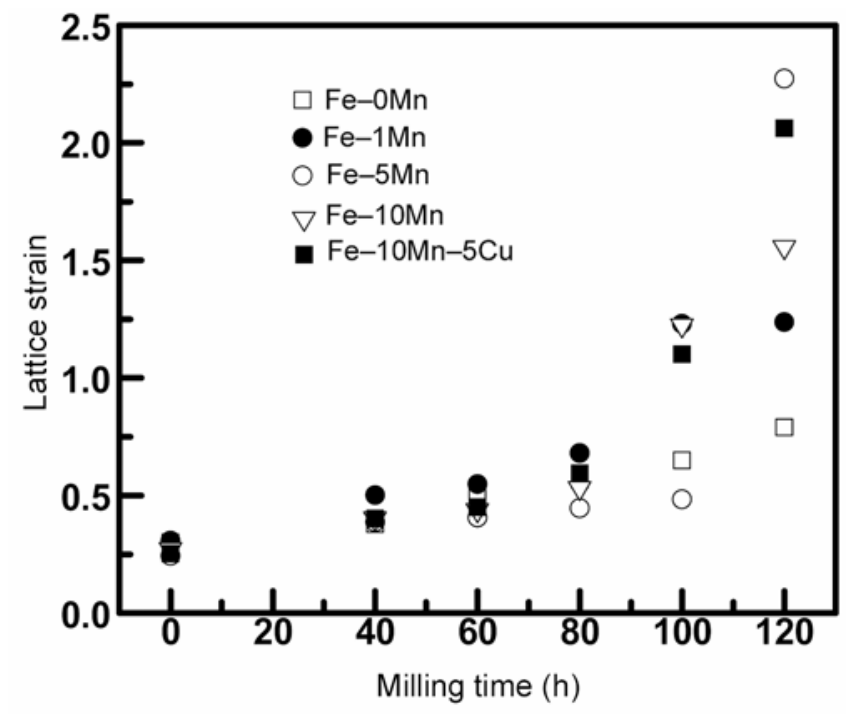

Figure 5. Variation of lattice strain vs milling time for various samples.

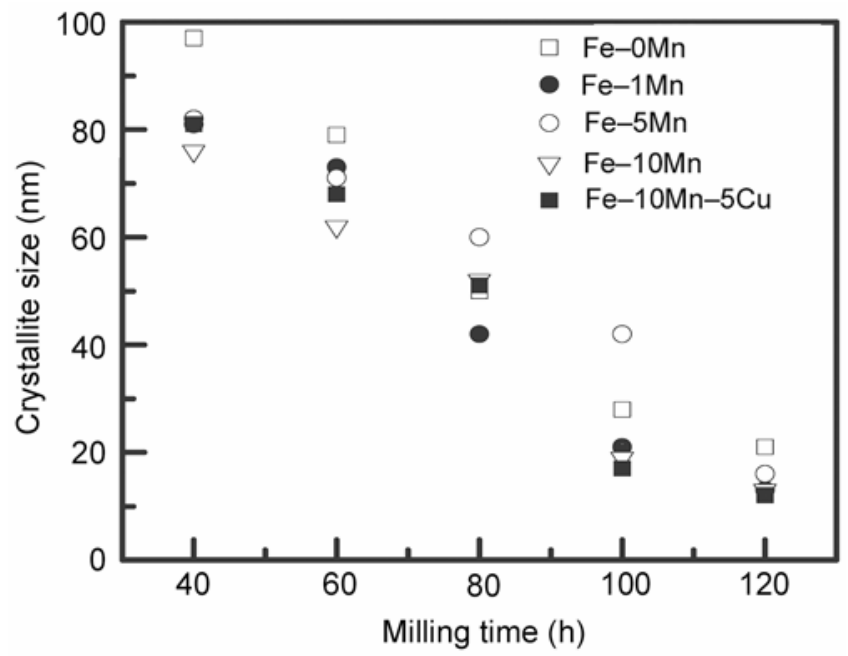

Figure 6. Variation of crystallite size vs milling time for various samples. 

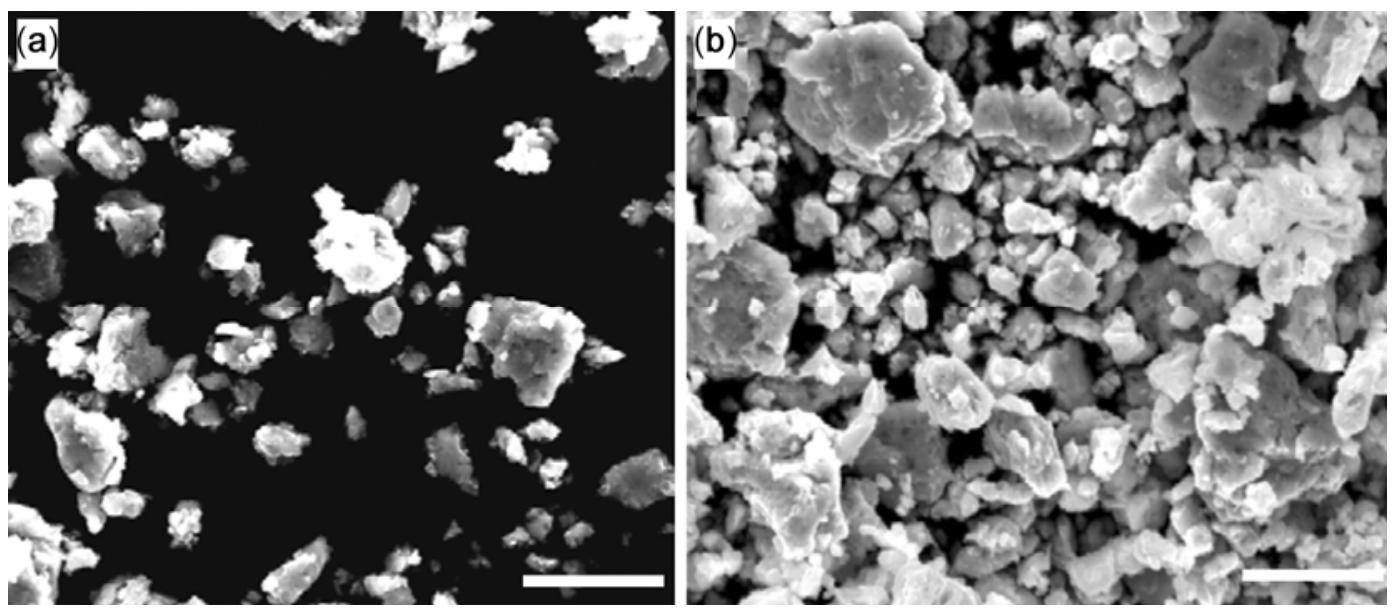

Figure 7. SEM micrographs of as-prepared powders after milling for $100 \mathrm{~h}$ : (a) $\mathrm{Fe}-0 \mathrm{Mn}$ and (b) $\mathrm{Fe}-1 \mathrm{Mn}$. Bar $=5 \mu \mathrm{m}$.

Table 2. Hyperfine parameter such as $B_{\mathrm{HF}}(\mathrm{kOe})$, IS $(\mathrm{mm} / \mathrm{s})$, QS $(\mathrm{mm} / \mathrm{s})$ and RA (\%) for various samples (obtained after $80 \mathrm{~h}$ of milling).

\begin{tabular}{|c|c|c|c|c|c|c|c|c|c|c|c|c|}
\hline \multirow[b]{2}{*}{ Sample } & \multicolumn{4}{|c|}{ First sextet } & \multicolumn{4}{|c|}{ Second sextet } & \multicolumn{4}{|c|}{ Doublet } \\
\hline & $B_{\mathrm{HF}}$ & IS & QS & RA & $B_{\mathrm{HF}}$ & IS & QS & RA & $B_{\mathrm{HF}}$ & IS & QS & RA \\
\hline $\mathrm{Fe}-0 \mathrm{Mn}$ & 331 & $0 \cdot 012$ & $0 \cdot 00$ & 18 & 241 & $0 \cdot 16$ & $-0 \cdot 01$ & 80 & - & $0 \cdot 34$ & $0 \cdot 81$ & 2 \\
\hline $\mathrm{Fe}-1 \mathrm{Mn}$ & 331 & $0 \cdot 011$ & $0 \cdot 00$ & 21 & 246 & $0 \cdot 16$ & $-0 \cdot 02$ & 77 & - & $0 \cdot 31$ & $0 \cdot 80$ & 2 \\
\hline $\mathrm{Fe}-5 \mathrm{Mn}$ & 331 & $0 \cdot 008$ & $0 \cdot 00$ & 18 & 208 & $0 \cdot 17$ & $-0 \cdot 01$ & 76 & - & 0.42 & $1 \cdot 25$ & 5 \\
\hline $\mathrm{Fe}-10 \mathrm{Mn}$ & 331 & $0 \cdot 006$ & $0 \cdot 00$ & 14 & 209 & $0 \cdot 15$ & $-0 \cdot 01$ & 81 & - & $0 \cdot 19$ & 1.05 & 5 \\
\hline $\mathrm{Fe}-10 \mathrm{Mn}-\mathrm{Cu}$ & 331 & 0.005 & $0 \cdot 00$ & 32 & 202 & $0 \cdot 22$ & -0.07 & 66 & - & $0 \cdot 35$ & 1.08 & 2 \\
\hline
\end{tabular}

$\mathrm{Fe}-10 \mathrm{Mn}-5 \mathrm{Cu}$ ) obtained after milling for $80 \mathrm{~h}$ are shown in figure 8 . For all the samples, the spectra show mainly two sextets and doublet. Both the sextets could be identified as iron-based phases having ferromagnetic characteristics, whereas the doublet could be due to the superparamagnetic component (Brand et al 1983) (figure 8). The hyperfine field $\left(B_{\mathrm{H}}\right)$, quadrupole split (QS) and isomer shift (IS) values of both sextets for all samples are tabulated in table 2. The $B_{\mathrm{H}}$ and QS values for all the first sextets were almost constant and around 331 and $0 \mathrm{kOe}$, respectively whereas IS value is found to decrease with $\mathrm{Mn}$ and $\mathrm{Cu}$ contents. Comparing with the hyperfine field of pure iron which is $330 \mathrm{kOe}$, it can be inferred that the Fe phase is devoid of any impurity (Varret et al 1982). The $B_{\mathrm{H}}$ value for the second sextet (second Febased phase) for $\mathrm{Fe}-0 \mathrm{Mn}$ was $241 \mathrm{kOe}$ which initially increases slightly for $\mathrm{Fe}-1 \mathrm{Mn}$ alloy and then decreases with further addition of $\mathrm{Mn}$ (table 2). The reduction of hyperfine field from 330 to $241 \mathrm{kOe}$ indicates that the environment of $\mathrm{Fe}$ atoms is enriched with the other alloying elements such as $\mathrm{Si}$ and $\mathrm{B}$, which is in conformity with the XRD results of solid solution formation. It is interesting to note that the hyperfine field increases slightly with the addition of Mn up to $1 \%$. The dilute solution of $\mathrm{Mn}$ in Fe environment might lead to coupling the spins between Fe and Mn ferromagnetically (Mirzoev et al 2009). Further increase of Mn favours antiferromagnetic coupling and thus decreases hyperfine field. The spectrum of $\mathrm{Fe}-10 \mathrm{Mn}-5 \mathrm{Cu}$ was different from the other spectra as it had relatively higher proportion of pure Fe-phase (figure 8 and table 2). This may be because of ferromagnetic coupling of $\mathrm{Mn}-\mathrm{Cu}$ (Bacon 1962). For all the samples, the proportion of doublet was quite low $(\sim 2-$ $5 \%$ ), which could be due to the absence of any paramagnetic or superparamagnetic component.

The magnetization vs field curve for the samples obtained after $120 \mathrm{~h}$ of milling are shown in figure 9. The corresponding values of $M_{\mathrm{s}}, H_{\mathrm{c}}$ and $M_{\mathrm{r}}$ for various samples are listed in table 1 . The $M_{\mathrm{s}}$ value for $\mathrm{Fe}-0 \mathrm{Mn}$ was found to be around $96.4 \mathrm{Am}^{2} / \mathrm{kg}$, which was reasonably lower than that of bulk Fe-4wt\% Si $\left(\sim 185 \mathrm{Am}^{2} / \mathrm{kg}\right)$ (Cullity 1972). The lower value of $M_{\mathrm{s}}$ could be due to the dissolution of alloying elements and due to the decrease in the crystallite size. The magnetic properties of the materials depend on the short-range ordering which may be described by the number, type, distance and symmetry of the nearest neighbours (Staunton et al 1998). The effect of dead or inert layer on the nanoparticles could also be responsible for this reduced value of $M_{\mathrm{s}}$. Lower value may also be due to the surface/interface pinning forces 

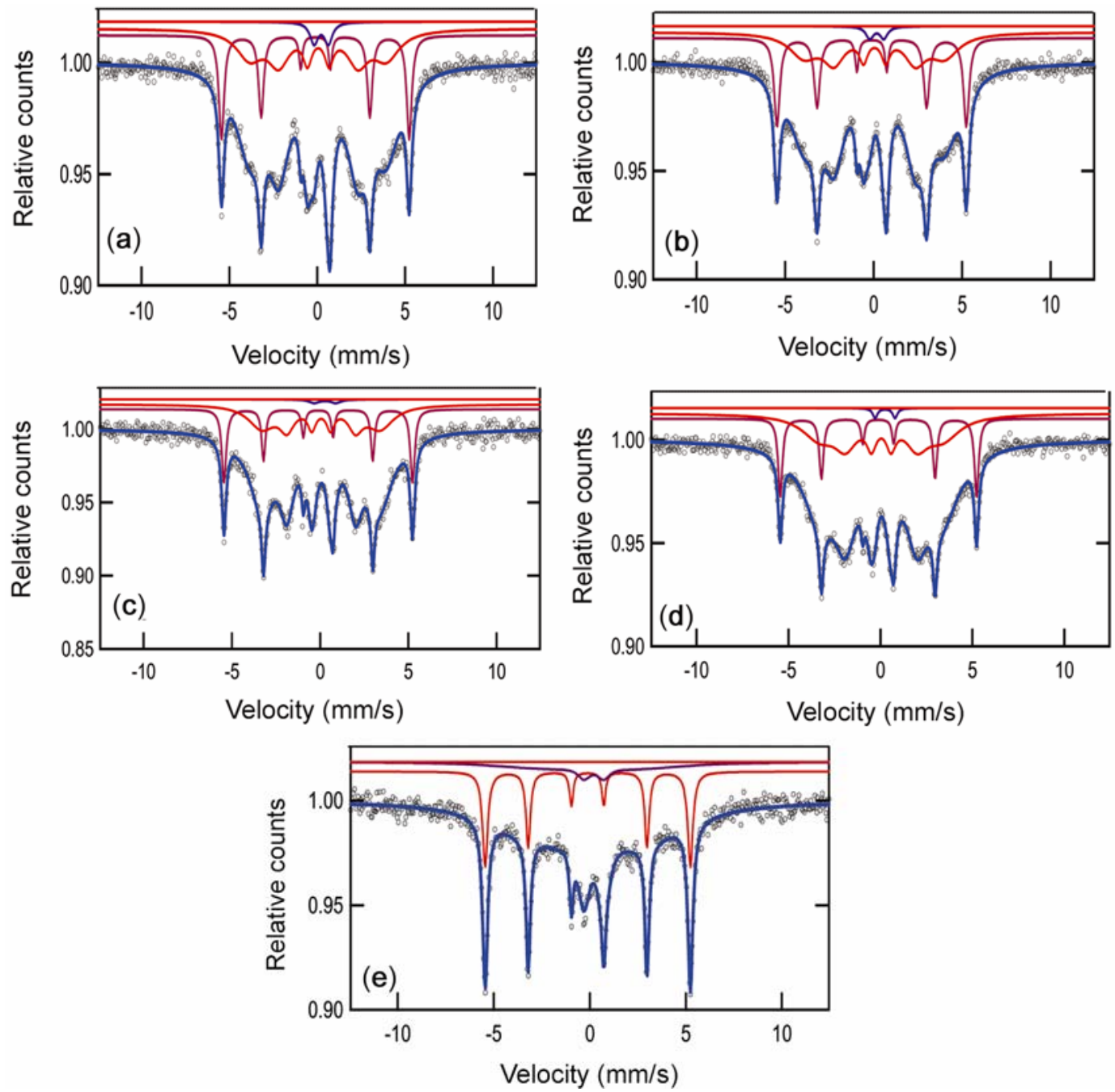

Figure 8. Mössbauer spectra of as-prepared powders after milling for $80 \mathrm{~h}$ (a) $\mathrm{Fe}-0 \mathrm{Mn},(\mathbf{b}) \mathrm{Fe}-1 \mathrm{Mn}$, (c) $\mathrm{Fe}-5 \mathrm{Mn}$, (d) $\mathrm{Fe}-10 \mathrm{Mn}$ and (e) $\mathrm{Fe}-10 \mathrm{Mn}-5 \mathrm{Cu}$.

which restricts the rotation of magnetization along the direction of the external field (Behvandi et al 2010).

Similar to the Mössbauer spectra, the $M_{\mathrm{s}}$ value initially increased and then decreased with $\mathrm{Mn}$. In general, the addition of $\mathrm{Mn}$ in Fe reduces both $M_{\mathrm{s}}$ and $B_{\mathrm{H}}$ values due to the antiferromagnetic coupling between them (Piramanayagam et al 1990). Mn has high single atom magnetic moment $\left(\sim 5 \mu_{\mathrm{B}}\right)$ as compared to that of $\mathrm{Fe}$ atom $\left(\sim 2 \cdot 6 \mu_{\mathrm{B}}\right)$, but couples antiferromagnetically between two $\mathrm{Mn}$ atoms. Therefore, when $\mathrm{Mn}$ is in dilute solution in $\mathrm{Fe}$, the $\mathrm{Mn}-\mathrm{Mn}$ interaction decreases which attributes to the escape from the formation of antiferromagnetic coupling leading to the enhancement of magnetic moment. With further increase of $\mathrm{Mn}, M_{\mathrm{s}}$ value decreases due to the increase of $\mathrm{Mn}-\mathrm{Mn}$ interaction. However, the magnetization further increases for $\mathrm{Fe}-10 \mathrm{Mn}-\mathrm{Cu}$ sample as compared to that of $\mathrm{Fe}-10 \mathrm{Mn}$ sample. As stated earlier that diamagnetic $\mathrm{Cu}$ after coupling with $\mathrm{Mn}$ can provide a momentum up to $2.4 \mu_{\mathrm{B}}$ per atom and it could be one of the reasons for enhanced $M_{\mathrm{s}}$ value of $\mathrm{Cu}$ containing alloy
(Bacon 1962). The Mössbauer spectrum of the Fe-10Mn$5 \mathrm{Cu}$ sample (figure 8 and table 2) also shows similar behaviour.

The $H_{\mathrm{c}}$ value for various samples obtained after milling for $120 \mathrm{~h}$ are given in table 1 . The coercivity for the samples was relatively higher $\left(\sim 8.44-12.42 \mathrm{kAm}^{-1}\right)$. It was even higher than the value reported for ball-milled product of $\mathrm{Fe}-\mathrm{Co}-\mathrm{V}$ or $\mathrm{Fe}-\mathrm{Ni}$ system (Behvandi et al 2010). Magnetic coercivity is an extrinsic and structure sensitive characteristic which essentially depends on the material structure, internal defects, residual stresses, grain size and nonmagnetic inclusions (Herzer 1997). It has been reported that $H_{\mathrm{c}}$ enhances due to the pinning of magnetic domain walls by the impurities or the nonmagnetic inclusions produced during mechanical alloying (Chen 1977). The large density of defects like dislocations or increased fraction of grain boundaries produced or the residual stress due to severe plastic deformation during the process also impede the domain walls movement and increase the coercivity (Bacon 1962). For Fe-10Mn-5Cu, 


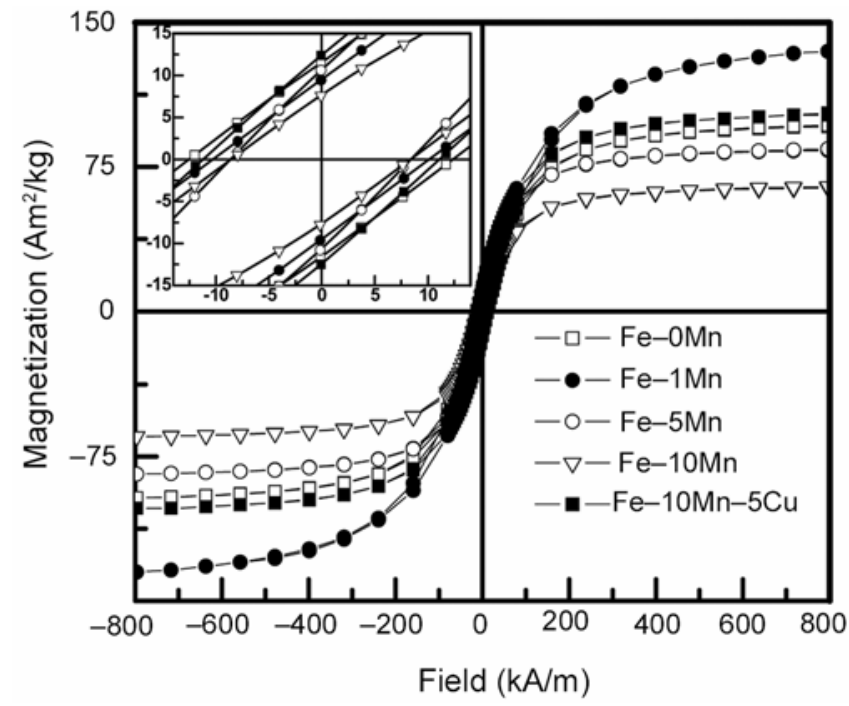

Figure 9. Magnetization vs applied magnetic field curve for as-prepared powders obtained after milling for $120 \mathrm{~h}$.

the $H_{\mathrm{c}}$ value was $10.98 \mathrm{kA} / \mathrm{m}$, which was higher than the values for only $\mathrm{Mn}$-substituted samples. The $M_{\mathrm{r}}$ values of all the samples were also relatively higher (table 1). Nevertheless, similar to $M_{\mathrm{s}}$ and $H_{\mathrm{c}}$ values, the $M_{\mathrm{r}}$ value initially increases and then decreases with increased Mn-addition (table 2), whereas the sample with $\mathrm{Cu}$ constituents had highest $M_{\mathrm{r}}$ value. The higher values of $M_{\mathrm{s}}$, $H_{\mathrm{c}}$ and $M_{\mathrm{r}}$ for $\mathrm{Fe}-10 \mathrm{Mn}-5 \mathrm{Cu}$ sample could be due to the suitable coupling between $\mathrm{Mn}$ and $\mathrm{Cu}$ (Bacon 1962).

\section{Conclusions}

Using high energy planetary ball mill, various alloys of $\mathrm{Fe}-\mathrm{Si}-\mathrm{B}$ with varying composition of $\mathrm{Mn} / \mathrm{Cu}$ were prepared. Almost a complete dissolution of $\mathrm{Si}$ was found after $80 \mathrm{~h}$ of milling but it took lesser time in the case of high $\mathrm{Mn}$ and $\mathrm{Cu}$ substitution. The dissolution of alloying elements in Fe was confirmed by XRD and FESEM/EDX study directly and indirectly by magnetic characterization. Due to the formation of alloys, the lattice parameter enhanced from $2 \cdot 8581$ to $2 \cdot 8881 \AA$ and strain increased from 0.25 to $2 \cdot 25$, whereas the crystallite size decreased from micrometer to nanometer $(10-20 \mathrm{~nm})$. Mössbauer spectra analysis suggests the presence of essentially ferromagnetic components in the system. Although, the $M_{\mathrm{s}}$ value for the milled samples $\left(64.7-134.8 \mathrm{Am}^{2} / \mathrm{kg}\right)$ was less than the bulk counterpart, but it was relatively higher for the samples containing low Mn or both $\mathrm{Mn}$ and $\mathrm{Cu}$. The $M_{\mathrm{r}}$ value was in the range of $7 \cdot 6-12.4 \mathrm{Am}^{2} / \mathrm{kg}$, whereas $H_{\mathrm{c}}$ value was in the range of $8.44-12.42 \mathrm{kA} / \mathrm{m}$, which was relatively more, hence, may provide better squareness ratio.

\section{Acknowledgement}

(NKP) and (NKM) thank DST, New Delhi, India, for financial support to sanction project related to magnetic materials and ball milling, respectively.

\section{References}

Ares J R and Cuevas F 2005 Acta Mater. 532157

Bacon G E 1962 Proc. Phys. Soc. 79938

Behvandi A, Shokrollahi H, Chitsazan B and Ghaffari M 2010 J. Magn. Magn. Mater. 3223932

Brand R A, Lauer J and Herlach D M 1983 J. Phys. F: Met. Phys. 13675

Chen C W 1977 Magnetism and metallurgy of soft magnetic materials (Amsterdam: North-Holland)

Cullity B D 1972 Introduction to magnetic materials (London: Addison Wesley)

Ebrahimi A, Ghaffari M and Janghorban K 2011 J. Magn. Magn. Mater. 323149

Filho A F, Bolfarini C, Xu Y and Kiminami C S 2000 Scr. Mater. 42213

Herzer G 1997 Handbook of magnetic materials (The Netherlands: Elsevier Science B V) Vol. 10

Hosseini H R M and Bahrami A 2005 Mater. Sci. Eng. B123 74

Koch C C 1993 Nanostruct. Mater. 2109

Liu T, Liu H Y, Zhao Z T, Ma R Z, Hu T D and Xi Y N 1999 Mater. Sci. Eng. A271 8

Majumdar B, Raja M M, Narayanasamy A and Chattopadhyay K 1997 J. Alloys Compd. 248192

Mirzoev A A, Mirzaev D A and Yalolov M M 2009 Proceedings of the World Congress on Engineering Vol. 1, WCE 2009, London, UK, ISBN: 978-988-17012-5-1

Mohamed A 2003 Acta Mater. 514107

Moumeni H, Alleg S and Greneche J M 2005 J. Alloys Compd. 38612

Okumura H, Ishihara K N, Shingu P H, Park H S and Nasu S 1992 J. Mater. Sci. 27153

Perez R J, Huang B, Crawford P J, Sharif A A and Lavernia E J 1995 Mater. Sci. Eng. A204 217

Piramanayagam S N, Shringi S N, Prasad S, Nigam A K, Chandra G, Krishnan R and Ramanan V R V 1990 Solid State Commun. 7693

Prasad N K, Panda D, Singh S, Mukadam M D, Yusuf S M and Bahadur D 2005 J. Appl. Phys. 97 10Q903

Staunton J B, Razee S S A, Ling M F, Johnson D D and Pinski F J 1998 J. Phys. D: Appl. Phys. 312355

Suryanarayana C 2001 Prog. Mater. Sci. 461

Suryanarayana C, Ivanov E and Boldyrev V V 2001 Mater. Sci. Eng. A151 304

Varret F, Hanzić A and Campbell I A 1982 Phys. Rev. B26 5285

Wu Y K, Huang J Y, He A Q, Hu K Y and Meng X M 1993 Acta Metall. Sinica B29 546

Yadav T P, Mukhopadhyay N K, Tiwari R S and Srivastava O N 2005 Mater. Sci. Eng. A393 366

Yapp R, Watts B E and Leccabue F 2000 J. Magn. Magn. Mater. 215300 